\title{
Limites e possibilidades do uso das TICs pela agricultura familiar na região Sul do Brasil
}

\author{
Wilson Itamar Godoy \\ Universidade Tecnológica Federal do Paraná - Pato Branco - Paraná - Brasil \\ ORCID: https://orcid.org/0000-0003-0152-6269 \\ Andressa Sanssanoviez \\ Universidade Tecnológica Federal do Paraná - Pato Branco - Paraná - Brasil \\ ORCID: https://orcid.org/0000-0002-9337-6263 \\ Giovanna Pezarico \\ Universidade Tecnológica Federal do Paraná - Curitiba - Paraná - Brasil \\ ORCID: https://orcid.org/0000-0001-5576-6685
}

\section{Resumo}

Estudos demonstram que as Tecnologias de Informação e Comunicação (TICs) podem auxiliar na emancipação dos usuários, oferecendo-lhes a possibilidade de acesso à informação e ao conhecimento a fim de se tornarem agentes de sua própria história. Nesse sentido, o objetivo desta investigação é analisar o uso das TICs por famílias agricultoras da região Sul do Brasil, apontando os limites e possibilidades no contexto da agricultura familiar. Para alcançar este objetivo, foi realizada a aplicação de formulários em trinta unidades familiares dos municípios de Xaxim/SC e Pato Branco/PR. A pesquisa verificou que a possibilidade de acessar e usar as TICs representa para os agricultores familiares uma necessidade frente à competitividade do mercado atual. Apesar da importância e significado que as TICS representam ao meio rural, o campo de estudo revela que as condições desse acesso apresentam limitações, pois o sistema técnico é deficitário, o que impede o efetivo acesso a todo o potencial que detêm essas tecnologias. Em alguns casos, mesmo com um investimento elevado, o agricultor não consegue acessar um serviço melhor ou mesmo usar adequadamente. Por fim, verifica-se que as TICs estão inseridas no contexto da agricultura familiar e representam a possibilidade de integração em rede e construção compartilhada de saberes.

Palavras-chave: Agricultura Familiar. Tecnologias de Informação e Comunicação. Desenvolvimento Rural. Informação. Comunicação.

\section{Abstract}

Limits and possibilities of the use of ICT by family agriculture in Southern Brazil

Studies demonstrate that Information and Communication Technologies (ICTs) can assist in the emancipation of users, offering them the possibility of accessing information and knowledge in order to become agents of their own history. In this sense, the objective of 
this investigation is to analyze the use of ICTs by farming families in the southern region of Brazil, pointing out the limits and possibilities in the context of family farming. To achieve this goal, forms were applied to thirty family units in the municipalities of Xaxim / SC and Pato Branco / PR. The research found that the possibility of accessing and using ICTs represents a need for family farmers in view of the competitiveness of the current market. Despite the importance and significance that ICTs represent to rural areas, the field of study reveals that the conditions of this access have limitations, as the technical system is deficient, which prevents effective access to all the potential that these technologies hold. In some cases, even with a high investment, the farmer cannot access a better service or even use it properly. Finally, it appears that ICTs are inserted in the context of family farming and represent the possibility of network integration and shared construction of knowledge.

Keywords: Family farming. Information and Communication Technologies. Rural Development. Information. Communication.

\section{Límites y posibilidades del uso de las TIC por la agricultura familiar en el Sur de Brasil Resumen}

Los estudios demuestran que las Tecnologías de la Información y la Comunicación (TIC) pueden ayudar en la emancipación de los usuarios, ofreciéndoles la posibilidad de acceder a información y conocimiento para convertirse en agentes de su propia historia. En este sentido, el objetivo de esta investigación es analizar el uso de las TIC por las familias de agricultores en la región sur de Brasil, señalando los límites y las posibilidades en el contexto de la agricultura familiar. Para lograr este objetivo, se aplicaron formularios a treinta unidades familiares en los municipios de Xaxim / SC y Pato Branco / PR. La investigación encontró que la posibilidad de acceder y utilizar las TIC representa una necesidad para los agricultores familiares en vista de la competitividad del mercado actual. A pesar de la importancia y la importancia que las TIC representan para las áreas rurales, el campo de estudio revela que las condiciones de este acceso tienen limitaciones, ya que el sistema técnico es deficiente, lo que impide el acceso efectivo a todo el potencial que tienen estas tecnologías. En algunos casos, incluso con una alta inversión, el agricultor no puede acceder a un mejor servicio o incluso usarlo adecuadamente. Finalmente, parece que las TIC se insertan en el contexto de la agricultura familiar y representan la posibilidad de integración de redes y construcción compartida de conocimiento.

Palabras clave: Agricultura familiar. Tecnologías de la Información y la Comunicación. Desarrollo rural. Información. Comunicación.

\section{Introdução}

A partir da Segunda Guerra Mundial, Castells (2010), afirma que houve um aumento do uso das tecnologias, sendo que, desde essa época, ocorreram as principais descobertas tecnológicas em eletrônica, tais como o primeiro computador programável e o transistor. Porém, somente a partir de 1970 as novas tecnologias da informação se difundiram de maneira ampla, convergindo em um novo paradigma. O mesmo autor afirma que o desenvolvimento das redes foi possível pelos avanços das telecomunicações e tecnologias que integravam os computadores em rede, ocorrido em 1970. No entanto, essas mudanças somente foram possíveis após o surgimento dos dispositivos microeletrônicos e a expansão da capacidade de computação, ou seja, a microeletrônica, os computadores e as 
telecomunicações, inter-relacionados, constituíram a revolução da tecnologia da informação.

No final dos anos 1990, ocorreu mais uma grande mudança tecnológica: a capacidade de comunicação da internet junto aos avanços em telecomunicações e a computação possibilitaram a interconexão de dispositivos móveis. Conforme Castells (2010, p. 89), "a lógica do funcionamento de redes, cujo símbolo é a Internet, tornou-se aplicável a todos os tipos de atividades, a todos os contextos e a todos os locais que pudessem ser conectados eletronicamente". Nesse sentido, Thompson (2008) afirma que, no mundo moderno, o desenvolvimento dos novos meios de comunicação tornou comuns novos tipos de relacionamentos sociais, fazendo surgir uma reorganização da interação humana, ultrapassando as barreiras de tempo e espaço e as interações face a face.

No decorrer dos anos, os avanços tecnológicos trouxeram mudanças nos sistemas de comunicação que envolvem o agricultor, através do vídeo, telefone celular, aumento de publicações especializadas, e particularmente, a internet transformaram as condições de acesso à informação. "Os relacionamentos e fontes de informação no meio rural ficaram fluidos, conectados por múltiplas redes e abrigados por instrumentos bastante variados de comunicação [...]" (DUARTE; CASTRO, 2004, p. 54).

Nesse sentido, Torres et. al. (2013) corroboram, afirmando que as TICs contribuem para promover a colaboração entre as pessoas e organizar atividades em comum. Além disso, possibilitam que pequenos agricultores sejam protagonistas desse espaço, compartilhando saberes e utilizando essas tecnologias como mediadoras, pois é por meio da troca e do intercâmbio de ideias que as pessoas geram e compartilham conhecimentos.

Os dados do Instituto Brasileiro de Geografia e Estatística/IBGE (2018) divulgados por meio da Pesquisa Nacional Por Amostra De Domicílios (PNAD) demonstram que o acesso à internet nos domicílios vem crescendo rapidamente, sendo em 2016 utilizada por 69,3\% dos domicílios, passando para 74,9\% dos domicílios com acesso à internet em 2017. No que diz respeito a outra TIC impulsionada com a revolução digital, o computador, ocorre um movimento inverso nos últimos anos, com uma redução do percentual de computadores nos lares. Em 2017, o computador era utilizado para acessar a internet por 52,3\% dos domicílios, o que demonstra um declínio em relação ao ano anterior, 2016, quando o computador era utilizado por 57,8\%. Ainda conforme a PNAD, em 2016, 97,2\% dos domicílios utilizavam o celular para acessar a internet, passando para $98,7 \%$ dos domicílios em 2017. Logo, constata-se a tendência de utilização cada vez mais frequente da internet por meio dos telefones celulares e em menor grau por meio do computador.

Apesar do crescente número de usuários que adotam as novas tecnologias, Viero e Silveira (2011) afirmam que a infraestrutura é um dos maiores problemas nas áreas rurais, além da falta de conteúdo específico para essas comunidades. Os dados do Censo Agropecuário 2017, divulgados pelo Instituto Brasileiro de Geografia e Estatística (2018), evidenciam que o acesso à internet tem aumentado significativamente no Brasil, apesar disso, observa-se que a maior parte dos estabelecimentos rurais, $72 \%$, ainda não possuem acesso à internet. 
A partir desse breve contexto, o objetivo deste artigo é analisar o uso das TICs por famílias agricultoras da região Sul do Brasil, apontando os limites e possibilidades desse uso no contexto da agricultura familiar. Para dar conta deste objetivo, a metodologia da pesquisa consistiu na coleta de dados por meio da aplicação de formulários semiestruturados, aplicados no domicílio de agricultores familiares localizados nos municípios de Xaxim/SC e Pato Branco/PR.

Estruturalmente, o artigo está dividido em três seções, além desta introdução e das considerações finais. Na primeira seção, explora-se teoricamente o tema do uso das Tecnologias de Informação e Comunicação no contexto da agricultura familiar. Na segunda, apresenta-se brevemente a metodologia do trabalho. Na terceira seção, discutem-se e analisam-se os principais resultados, abordando-se os limites e possibilidades do uso das TICs pela agricultura familiar.

\section{0 uso das TICs pela agricultura familiar}

O novo sistema de comunicação está mudando e continuará a mudar a cultura. A comunicação molda a cultura, e, com o passar do tempo, crenças e códigos se transformarão pelo novo sistema tecnológico. O novo sistema de comunicação transforma o espaço e tempo, as localidades integram-se em redes e se desprendem do sentido cultural e histórico do qual fazem parte (CASTELLS, 2010).

Nesse contexto, Thornton (2003) afirma que a convergência de diversos processos tecnológicos, através de redes de computadores e telefonia, está mudando o modo de relacionamento social e as questões culturais e, portanto, o mundo rural. Para o autor, a internet permite que as pessoas estejam em todos os lugares e em tempo real. Nessa dinâmica, aos poucos as novas tecnologias vão sendo apropriadas pela população rural, possibilitando uma ampliação nos canais em que recebem informações. "Dessa maneira, os atores rurais podem confirmar, analisar, ampliar e até questionar as mensagens transmitidas diariamente" (CONCEIÇÃO, 2012, p. 31).

A inserção das TICs no contexto da agricultura familiar representa inúmeras potencialidades, com destaque para questões relacionadas às mulheres e aos jovens. Silva (2016) afirma que a apropriação das TICs pela mulher ampliou a sua participação nos processos decisórios da propriedade rural familiar, pois, munida de informações, a mulher se tornou responsável por administrar os recursos e investimentos do empreendimento familiar, conquistando o respeito do marido, dos filhos e da comunidade, o que tem reflexo direto em sua autoestima e empoderamento.

Além disso, as TICs representam para as mulheres uma condição de integração familiar, uma vez que por meio da incorporação, tornaram-se mantenedoras dos vínculos familiares, utilizando essas tecnologias, principalmente para a comunicação com os familiares (ESCOSTEGUY; SIFUENTES; BIANCHINI, 2019).

No que se refere ao uso das TICs pelas novas gerações de produtores, Centeno (2016) destaca que os jovens não somente incorporam as TICs em suas atividades diárias, mas também reconfiguram muitos modos tradicionais de fazer e viver a agricultura. A inserção das TICs nas atividades cotidianas pode contribuir e estimular a produção de novidades, auxiliando nas atividades agrícolas e pecuárias. 
Os jovens também possuem uma forma particular de transitar entre o rural e o urbano, utilizando telefones móveis, que se constituem como uma excelente plataforma de conexão entre esses espaços. O estudo de Felippi, Guerin e Oliveira (2019), corrobora no sentido de que a posse e uso das TICs pelos jovens torna-se quase uma condição para pertencer a um grupo. Além disso, as TICs representam aos jovens a intensificação da troca de informações, agilidade e flexibilidade nos processos, bem como a aproximação e maior interatividade.

Nesse sentido, Blanco e Cánoves (2005) afirmam que as Tecnologias de Informação e Comunicação impactam diretamente tanto nos territórios e nas sociedades envolvidas nelas, quanto naquelas que não podem ser incorporadas em seu raio de ação. Dessa forma, as TICs podem favorecer a implantação de novas iniciativas produtivas em áreas que têm sofrido acelerado processo de despovoamento, principalmente naquelas regiões frágeis e desfavorecidas pela sua localização. Ao mesmo tempo, a falta delas supõe uma desigualdade dentro das novas redes, perda de possibilidade de desenvolvimento e, portanto, um declínio desses territórios. Abramovay (2000), complementa que o rural e o urbano devem ser olhados de maneira conjunta, e não separados, o que tornaria possível o desenvolvimento do território.

A sociedade informacional e o desenvolvimento local devem estar inevitavelmente unidos. A compreensão da ruralidade contemporânea pode oferecer um apoio às políticas públicas destinadas as TICS, e assim, colaborar com o desenvolvimento rural e regional. "Abolir as distâncias espaciais e oportunizar acesso universal às TICs são promessas da nova configuração da sociedade" (VIERO; SOUZA, 2008, p. 6). No entanto, para que isso ocorra, torna-se necessário a superação de questões relacionadas aos custos de infraestrutura, qualificação da população para a utilização e a familiaridade com a Internet.

O estudo de Lardone (2013) considera que, em um mundo com fronteiras móveis e em disputa, o espaço rural deve-se integrar ao coletivo social de conhecimentos compartilhados. Para isso, é preciso entender que o fim não são as TICs, elas são apenas instrumentos para ajudar a construir sociedades mais participativas, inclusivas e colaborativas. Os projetos tecnológicos apoiados pelas TICs para as áreas rurais devem ter como objetivo a solução de problemas e suas próprias necessidades, respeitando a heterogeneidade da parcela onde estão inseridos os territórios urbano-rurais.

Adicionalmente, a mesma autora afirma que é preciso considerar a inclusão digital do rural para além de uma solução, mas como uma instância nodal, que permite e facilita a inserção da vida rural na sociedade do conhecimento e viceversa. Isto é, a partir de seus particularismos, a comunicação como prática e processo pode ser um valioso aporte ao diálogo multidisciplinar e, acima de tudo, colaborar na reparação da ruptura histórica campo-cidade.

\section{Metodologia da pesquisa}

Nesta seção, serão abordados os procedimentos metodológicos utilizados para alcançar os objetivos propostos para esta pesquisa. Como já mencionado, o objetivo deste trabalho/pesquisa foi analisar o uso das TICs por famílias agricultoras da região Sul do Brasil, apontando os limites e possibilidades no contexto da 
agricultura familiar. O estudo foi realizado na cidade de Xaxim, região Oeste de Santa Catarina, e em Pato Branco, Sudoeste do Paraná. Foram incluídos na pesquisa agricultores familiares que residem no meio rural dos referidos municípios, devido a agricultura familiar ser uma categoria predominante em ambos os locais. Adotou-se o conceito de agricultura familiar conforme a Lei $n^{\circ} 11.326$ de 2006, que define 0 agricultor familiar como aquele que pratica atividades no meio rural, atendendo, simultaneamente, aos seguintes requisitos:
I - não detenha, a qualquer título, área maior do que 4 (quatro) módulos fiscais;
II - utilize predominantemente mão-de-obra da própria família nas atividades econômicas do seu estabelecimento ou empreendimento; III - tenha percentual mínimo da renda familiar originada de atividades econômicas do seu estabelecimento ou empreendimento, na forma definida pelo Poder Executivo; (Redação dada pela Lei no 12.512, de 2011) IV - dirija seu estabelecimento ou empreendimento com sua família (BRASIL, 2006).

De acordo com os dados do Censo Agropecuário de 2006, divulgados pelo Instituto Brasileiro de Geografia e Estatística/IBGE (2006), em Pato Branco/PR, 247 estabelecimentos rurais (22\%) não são considerados unidades de agricultura familiar, enquanto 859 (78\%) são caracterizados como unidades de agricultura familiar. Em relação ao município de Xaxim/SC, 249 estabelecimentos rurais (19\%) não são considerados de agricultura familiar, enquanto 1.045 (81\%) são caracterizados como unidades de agricultura familiar. Nesta perspectiva, visualizase a importância e predominância da agricultura familiar nas regiões supracitadas.

Para a seleção da amostra, foram utilizados alguns critérios tais como: adequação do entrevistado ao conceito de agricultor familiar, respeitando a quantidade de módulos fiscais, bem como pertencer a uma das classes de atividades: A - produtor(a) de grãos; B - produtor(a) de leite; C - produtor(a) de hortícolas; D - produtor(a) que possui agroindústria familiar; e E - produtor(a) integrado. Assim sendo, foram entrevistados cinco produtores de grãos, oito produtores de leite, seis produtores de hortícolas, quatro que possuem agroindústria familiar e sete produtores integrados. Foram definidas essas categorias, considerando a diversidade que compõe a agricultura familiar, pois, em um mesmo local, os estabelecimentos rurais se diferenciam conforme seus objetivos de produção, superfície, mecanização, capacidade financeira, entre outros fatores. Com base nos critérios supracitados, a escolha das famílias entrevistadas ocorreu com o auxílio de órgãos/empresas que prestam serviços de fomento, assistência técnica e extensão rural nos municípios.

Foram entrevistadas cinco instituições ligadas ao rural em cada um dos municípios, sendo que cada instituição indicou três famílias agricultoras, as quais deveriam estar de acordo com os critérios estipulados para a seleção. A pesquisa englobou a participação de 30 famílias agricultoras, sendo selecionadas 15 famílias no município de Xaxim/SC e 15 famílias no município de Pato Branco/PR, distribuídas em vários pontos do território rural, não havendo, portanto, a seleção de uma comunidade específica. 
A coleta de dados ocorreu por meio da aplicação de formulários semiestruturados, que continham perguntas abertas e fechadas, realizado no domicílio dos agricultores familiares selecionados, estendendo-se entre os meses de agosto, setembro e outubro de 2019. Cabe ressaltar, que foi entrevistado o(a) responsável pelo estabelecimento rural, sendo orientado(a) para que respondesse as perguntas conforme as características da sua família.

Os questionamentos que basearam este artigo estão relacionados ao perfil das famílias entrevistadas, o que contribui para compreender o contexto dos entrevistados. Foram abordadas questões relativas à escolaridade, membros da família, área da unidade familiar e atividades econômicas desenvolvidas na unidade familiar. Além disso, questionou-se acerca do uso das TICs e bem como a finalidade desse uso, também as possibilidades e os principais problemas relacionados ao uso das TICS na unidade familiar.

Este estudo caracteriza-se como descritivo, considerando que o objetivo desse tipo de investigação é a descrição das características da população ou fenômeno em estudo (GIL, 2010). No que tange a análise dos dados coletados, adotou-se a abordagem qualitativa e quantitativa, pois conforme Minayo (2009, p. 22), "entre eles há uma oposição complementar que, quando bem trabalhada teórica e praticamente, produz uma riqueza de informações, aprofundamento e maior fidedignidade interpretativa". Entende-se que a abordagem qualitativa dá suporte à quantitativa, obtendo-se assim, uma análise mais aprofundada das informações obtidas no campo de estudo. A partir desse pressuposto, abordam-se a seguir os principais pontos levantados nesta pesquisa de campo.

\section{Apresentação dos resultados e discussões}

A partir do estudo de campo, manifestam-se uma série de reflexões sobre o lócus de pesquisa. A singularidade observada no campo de estudo se assemelha aos estudos de Brandemburg (2010), em que afirma que o rural brasileiro é composto por vários tempos, o que dificulta generalizações, portanto, desconsiderar essas diferenças pode resultar em equívocos. Nesse sentido, compreender a realidade vivenciada pelos atores que compõem o meio rural, suas potencialidades e desafios, permite que ações sejam pensadas e executadas no sentido de cooperar com o desenvolvimento dos territórios.

A partir desse pressuposto, são descritas características que ajudam a compreender o perfil da amostra e a realidade em que os participantes desta pesquisa estão inseridos. Ressalta-se que este estudo não objetiva comparar os locais estudados, e sim compreender as singularidades e configurações que cada espaço possui. A Tabela 1 apresenta uma síntese com as principais características sobre o perfil das unidades familiares pesquisadas no município de Pato Branco/PR. 
Tabela 1 - Perfil das unidades familiares entrevistadas em Pato Branco/PR

\begin{tabular}{|c|c|c|c|c|c|c|}
\hline $\begin{array}{l}\text { Identi- } \\
\text { ficação }\end{array}$ & $\begin{array}{c}\text { Idade } \\
\text { Entre- } \\
\text { vistado }\end{array}$ & Gênero & Escolari-dade & $\begin{array}{c}\mathrm{N}^{\circ} \text { de } \\
\text { Membros } \\
\text { família }\end{array}$ & $\begin{array}{l}\text { Área unidade } \\
\text { familiar (ha) }\end{array}$ & $\begin{array}{l}\text { Principal } \\
\text { atividade } \\
\text { econômica }\end{array}$ \\
\hline $\mathrm{AF} 1$ & 37 & $M$ & Ensino superior & 3 & 80 & Grãos \\
\hline AF 2 & 43 & $M$ & Ensino médio & 5 & 7,2 & $\begin{array}{c}\text { Agroindústria } \\
\text { de leite }\end{array}$ \\
\hline $\mathrm{AF}_{3}$ & 54 & $M$ & $\begin{array}{c}\text { Ensino } \\
\text { fundamental }\end{array}$ & 3 & 12,5 & Horticultura \\
\hline $\mathrm{AF}_{4}$ & 32 & $M$ & Ensino médio & 2 & 6 & Horticultura \\
\hline $\mathrm{AF} 5$ & 47 & M & Ensino médio & 2 & 16,6 & Avicultura \\
\hline AF 6 & 35 & $\mathrm{~F}$ & $\begin{array}{c}\text { Ensino } \\
\text { fundamental }\end{array}$ & 4 & 1,2 & Horticultura \\
\hline $\mathrm{AF} 7$ & 60 & M & Ensino médio & 1 & 5,7 & Avicultura \\
\hline AF 8 & 51 & $\mathrm{~F}$ & $\begin{array}{c}\text { Ensino } \\
\text { fundamental }\end{array}$ & 2 & 5 & Horticultura \\
\hline AF 9 & 29 & M & Ensino médio & 4 & 14,5 & Leite \\
\hline AF 10 & 42 & $\mathrm{~F}$ & Ensino médio & 6 & 24 & Avicultura \\
\hline AF 11 & 52 & M & $\begin{array}{c}\text { Ensino } \\
\text { fundamental }\end{array}$ & 4 & 33 & Grãos \\
\hline AF 12 & 60 & $\mathrm{~F}$ & $\begin{array}{c}\text { Ensino } \\
\text { fundamental }\end{array}$ & 2 & 16,8 & Grãos \\
\hline AF 13 & 48 & $M$ & $\begin{array}{c}\text { Ensino } \\
\text { fundamental }\end{array}$ & 4 & 3,4 & $\begin{array}{l}\text { Agroindústria } \\
\text { de embutidos }\end{array}$ \\
\hline AF 14 & 63 & $\mathrm{~F}$ & $\begin{array}{c}\text { Ensino } \\
\text { fundamental }\end{array}$ & 2 & 37 & Leite \\
\hline AF 15 & 65 & M & $\begin{array}{c}\text { Ensino } \\
\text { fundamental }\end{array}$ & 2 & 19 & Leite \\
\hline
\end{tabular}

Fonte: Coleta e análise de dados.

De igual modo, a Tabela 2 apresenta uma síntese com as principais informações que compõem o perfil das unidades familiares pesquisadas no município de Xaxim/SC. 
Tabela 2 - Perfil das unidades familiares entrevistadas em Xaxim/SC

\begin{tabular}{|c|c|c|c|c|c|c|}
\hline $\begin{array}{l}\text { Identi- } \\
\text { ficação }\end{array}$ & $\begin{array}{c}\text { Idade } \\
\text { Entre- } \\
\text { vistado }\end{array}$ & Gênero & Escolari-dade & $\begin{array}{c}\mathrm{N}^{\circ} \text { de } \\
\text { Membros } \\
\text { família }\end{array}$ & $\begin{array}{c}\text { Área } \\
\text { unidade } \\
\text { familiar (ha) }\end{array}$ & $\begin{array}{l}\text { Principal } \\
\text { atividade } \\
\text { econômica }\end{array}$ \\
\hline AF 16 & 51 & M & $\begin{array}{c}\text { Ensino } \\
\text { fundamental }\end{array}$ & 5 & 44 & Grãos \\
\hline AF 17 & 26 & M & Ensino médio & 2 & 12,7 & Leite \\
\hline $\mathrm{AF} 18$ & 51 & $\mathrm{~F}$ & $\begin{array}{c}\text { Ensino } \\
\text { fundamental }\end{array}$ & 2 & 24 & Leite \\
\hline AF 19 & 51 & $M$ & $\begin{array}{c}\text { Ensino } \\
\text { fundamental }\end{array}$ & 2 & 20 & Avicultura \\
\hline AF 20 & 54 & $\mathrm{~F}$ & $\begin{array}{c}\text { Ensino } \\
\text { fundamental }\end{array}$ & 3 & 27,9 & Leite \\
\hline AF 21 & 52 & $\mathrm{~F}$ & $\begin{array}{c}\text { Ensino } \\
\text { fundamental }\end{array}$ & 2 & 15 & Leite \\
\hline AF 22 & 30 & M & Ensino superior & 4 & 14 & Grãos \\
\hline AF 23 & 59 & $M$ & $\begin{array}{c}\text { Ensino } \\
\text { fundamental }\end{array}$ & 4 & 24,2 & Avicultura \\
\hline AF 24 & 33 & $\mathrm{~F}$ & Ensino médio & 4 & 12 & Avicultura \\
\hline AF 25 & 37 & $\mathrm{~F}$ & Ensino superior & 6 & 9,2 & Leite \\
\hline AF 26 & 21 & M & Ensino superior & 4 & 12,5 & Avicultura \\
\hline AF 27 & 53 & M & Ensino médio & 5 & 12,5 & Horticultura \\
\hline AF 28 & 59 & M & Ensino superior & 3 & 9,1 & Horticultura \\
\hline AF 29 & 48 & M & $\begin{array}{c}\text { Ensino } \\
\text { fundamental }\end{array}$ & 5 & 14 & $\begin{array}{l}\text { Agroindústria } \\
\text { de queijos }\end{array}$ \\
\hline $\mathrm{AF} 30$ & 25 & M & Ensino médio & 3 & 12 & $\begin{array}{c}\text { Agroindústria } \\
\text { de açúcar de } \\
\text { cana }\end{array}$ \\
\hline
\end{tabular}

Fonte: Coleta e análise de dados.

As tabelas 1 e 2 demonstram a configuração dos agricultores familiares entrevistadas nos municípios de Pato Branco/PR e Xaxim/SC. A partir dos dados coletados, visualiza-se que a idade média dos entrevistados responsáveis pelo estabelecimento rural é de 43 anos em Xaxim/SC e 47 anos no município de Pato Branco/PR. A idade dos respondentes demonstra que a amostragem estudada não se configura como um espaço jovem. Além disso, o número de membros por família evidencia que um grande número de unidades familiares é composto apenas pelo casal, ou por idosos, compreendendo quatro ou cinco membros por unidade familiar.

Os dados coletados apontam que 50\% dos respondentes frequentou 0 ensino fundamental, $33 \%$ dos entrevistados o ensino médio e $17 \%$ o ensino superior, ou seja, metade dos entrevistados frequentou apenas o nível fundamental. Ademais, constata-se um indicador significativo no que tange ao tamanho das unidades familiares, em que, das 30 famílias entrevistadas, 19 possuem até um módulo fiscal. Percebe-se que o tamanho da propriedade está relacionada ao tipo das explorações, sendo que a tendência das explorações menores está direcionada a produção de hortícolas, agroindústria familiar e produção de leite. Além disso, são as menores propriedades as mais diversificadas. 
A partir da compreensão do perfil das unidades familiares entrevistadas, analisam se os limites e possibilidades do uso das TICs pelas famílias agricultoras incluídas neste estudo. Crovi (2008) define o uso como o exercício ou prática habitual e contínua de um dispositivo tecnológico. Adicionalmente, Proulx (2016, p. 44), entende que "o uso é o que as pessoas fazem, efetivamente, com os objetos e dispositivos técnicos". A partir do aporte teórico, os dados da pesquisa de campo evidenciam que, predominantemente, quem mais usa e faz essa intermediação, capta as informações e conhecimentos e as difunde, são os jovens e as mulheres.

O Fernando (filho) usa mais, depois a mãe dele. Geralmente usa o celular, o computador é mais pra pesquisa. [...] Mais é para questão da agropecuária, precisa um medicamento, dá uma pesquisada, o animal tem tal sintoma, ou você procura o veterinário e explica pra ele o que está acontecendo ou já vai buscar direto. (AF 26)

A minha esposa usa mais, eu só uso para fazer e receber ligação. Negócio de internet eu não sei. A minha esposa usa para fazer tudo, até para plantar orquídea, pesquisa doenças, problemas de saúde, medicamentos para usar. (AF 15)

Os relatos demonstram que o uso das TICs perpassa por múltiplos aspectos sendo incorporados na rotina das famílias de diversos modos. Percebe-se que as mulheres, e de maneira especial os jovens, são os protagonistas na inserção das famílias ao uso das TICs contribuindo com o aprimoramento das atividades na unidade familiar. Neste sentido o estudo de Schwartz (2012) também revelou que o acesso e o uso das TICS podem contribuir para o empoderamento das mulheres rurais, considerando que esse processo se desenvolve por meio do maior acesso à informação. Mais informadas, as mulheres conhecem mais e melhor a realidade em que vivem e as possibilidades que essa realidade lhes oferece, além de fortalecer e estreitar os vínculos afetivos e produtivos existentes, bem como criar novas redes.

Também complementa, a pesquisa de Escosteguy, Sifuentes e Bianchini (2019), a qual evidencia que as TICs são utilizadas pelas mulheres como um modo de narrar suas próprias vidas, esse processo se manifesta principalmente por meio de redes sociais. Nesse sentido, percebe-se a frequente possibilidade de uso das TICS pelas mulheres, oferecendo-lhes a oportunidade de acesso à informação e uma maior comunicação com os familiares, de outra forma, as TICs apresentam-se como fundamentais para o desenvolvimento das atividades produtivas e sociais dos estabelecimentos rurais. Ainda, no que tange ao uso das TICs pelos jovens, o estudo de Felippi e Escosteguy (2017) sobre o consumo de Tecnologias de Informação e Comunicação (TICs) entre jovens rurais, evidencia que os modos de viver dos jovens estão sendo afetados e reorganizados a partir da inserção das TICs, de modo especial, com a chegada da internet e do telefone celular no espaço rural.

Nessa perspectiva, o uso das TICs no ambiente das unidades familiares pesquisadas abrange múltiplos aspectos. Assim, no instrumento foram definidas as seguintes áreas de interesse (gráfico 1): produção, educação, uso de redes sociais e entretenimento. Posteriormente, foi explorado nas entrevistas os usos (quadro 1) com as características que compreendem cada uma das categorias de uso das TICS nas unidades familiares entrevistadas. 
Gráfico 1 - Uso das TICs nas unidades familiares entrevistadas por área de interesse

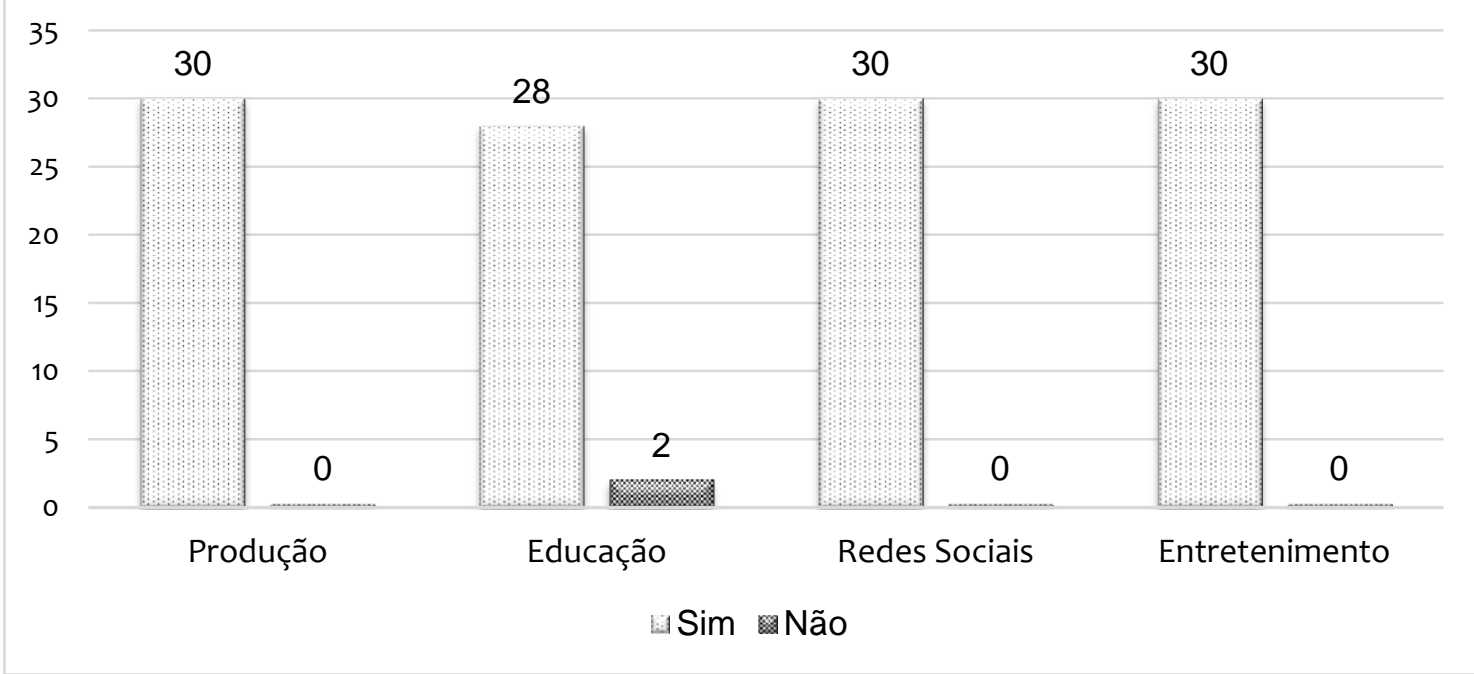

Fonte: Coleta e análise de dados.

Quadro 1 - Síntese das formas de uso das TICs nas unidades familiares

\begin{tabular}{|c|c|}
\hline Produção & $\begin{array}{l}\text { - Busca de informações relacionadas as atividades agropecuárias. } \\
\text { - Uso para planilhas e gestão da propriedade. } \\
\text { - Pagamento de contas e atividades governamentais. } \\
\text { - Pedidos de ração, medicamentos, entre outros. }\end{array}$ \\
\hline Educação & $\begin{array}{l}\text { - Educação à distância, incluindo cursos, palestras e atividades de } \\
\text { aperfeiçoamento. } \\
\text { - Jardinagem, panificação, cuidados com a saúde, entre outros. }\end{array}$ \\
\hline Redes Sociais & $\begin{array}{c}\text { - Comunicação e troca de informações com familiares, amigos, } \\
\text { comunidade, cooperativa entre outros atores, principalmente por meio de } \\
\text { aplicativos como WhatsApp e Facebook. } \\
\text { - Compra e venda de produtos. } \\
\text { - Agendamento de consulta, dentista, contato com veterinário. } \\
\text { - Pesquisa de preços, entre outros. }\end{array}$ \\
\hline Entretenimento & - Vídeos, filmes, jogos, entre outros. \\
\hline
\end{tabular}

Fonte: Coleta e análise de dados.

Os dados demonstram que $100 \%$ das famílias usam as TICs para buscar assuntos relacionados à produção, ao uso de redes sociais e para o entretenimento, sendo que $93,3 \%$ das famílias disseram que usam essas tecnologias para assuntos relacionados à educação. Conforme Conceição (2016), as TICs possibilitam múltiplas dimensões de empoderamento da agricultura familiar. A pesquisadora demonstra, por exemplo, que os agricultores familiares visualizam e utilizam a internet como um fator que contribui para a construção de capacidades econômicas, sociais e cognitivas, de modo a facilitar o desenvolvimento rural como um todo. Nesse sentido, observou-se neste estudo o interesse das famílias agricultoras em usar as TICs para múltiplos assuntos, que perpassam pela produção, educação, redes sociais e entretenimento. 
A partir do diálogo com as famílias entrevistadas, percebeu-se que a principal configuração de uso está centrada no contato com os familiares ou atores envolvidos nas atividades relacionadas à unidade familiar. Além disso, são usadas para informarem-se sobre jardinagem, panificação, cuidados com a saúde, entretenimento e contato com a família, entre outras inúmeras possibilidades que essas tecnologias oferecem. Entre as famílias, ocorre o uso de aplicativos para entretenimento e redes sociais, sendo os mais relatados o Whatsapp e o Facebook. Além disso, o uso das TICs para a educação à distância apresenta-se como uma possibilidade valiosa, de modo especial para as famílias que residem distante dos centros urbanos e cujos membros não teriam condições de fazer um curso tendo que sair da unidade familiar. A partir desse contexto, observa-se que as novas tecnologias atuam nessa mediação entre as famílias e o aperfeiçoamento educacional, pessoal e produtivo.

Entre as aplicabilidades mais frequentes e inovadoras do uso das TICs, estão o pagamento de contas por meio de aplicativos, pesquisa de preços, atividades e serviços governamentais, comércio eletrônico de variados produtos relacionados ao domicílio ou atividades produtivas, seja para a compra ou venda de mercadorias, entre outras possibilidades. O estudo de campo revelou ainda que 93,3\% das famílias entrevistadas já realizou algum tipo de compra ou venda pela internet, sendo que apenas $6,7 \%$ das famílias ainda não exerceu esse tipo de atividade.

Nesse cenário, verifica-se que a associação do uso de tecnologias pode representar um grande potencial no fortalecimento da produção de alto valor agregado. Além disso, o uso das TICs pode auxiliar os estabelecimentos rurais e torná-los mais eficientes e competitivos, facilitando principalmente a comercialização dos produtos com locais antes inacessíveis.

Essa característica associa-se ao estudo realizado por Conceição e Freitas (2018), o qual evidencia que o uso das TICs, principalmente por meio das redes sociais, tem reconfigurado a comercialização de alimentos. E dessa forma, possibilita a construção de novos mercados e contribui para encurtar distâncias entre produtores e consumidores, auxiliando na configuração das cadeias curtas de comercialização. Ainda conforme os autores, as TICs tendem a facilitar o processo de comunicação e favorecer a venda da produção. Os produtos ganham visibilidade através da divulgação em sites, redes sociais, formação de grupos, o que operacionaliza a comercialização e amplia o contato entre o agricultor e $o$ consumidor final.

Nesse sentido, as TICs configuram-se como uma significativa porta de entrada para o agricultor em novos mercados, ampliando horizontes, permitindo o estabelecimento de novas relações sociais com fornecedores e consumidores e ainda mediando as relações entre atores urbanos e rurais em mercados nunca antes possível de acessar da propriedade rural.

Hoje dá pra dizer que eu compro mais coisas pela internet do que na cidade (AF 1).

Hoje em dia é muito fácil você comprar. Eu só compro pelo mercado livre, nunca tive um problema com isso. Tudo certinho (AF 2). 
Os excertos revelam que a internet têm atuado nessa mediação, sendo considerada preponderante para o desenvolvimento das atividades dos estabelecimentos rurais. A partir dos relatos, percebe-se que as famílias afirmam que não precisam gastar dinheiro fazendo ligações ou ir até o local para saber se há ou não interesse no produto que oferecem ou necessitam, pois a internet intermedia esse processo. O desenvolvimento dos novos meios de comunicação tornou comum novos tipos de relacionamentos sociais, fazendo surgir uma reorganização da interação humana, ultrapassando as barreiras de tempo e espaço e as interações face a face. Desse modo, a interação se dissocia do ambiente físico, de tal maneira que os atores podem interagir uns com os outros, mesmo que não compartilhem do mesmo ambiente espaço-temporal (THOMPSON, 2008).

Na perspectiva de Conceição (2016), as TICs promovem novas formas de trabalho, aumento na renda da propriedade, que se torna mais conhecida por meio das redes sociais ou sites. Além disso, contribuem para fortalecer os processos de socialização no meio rural e aos poucos são aproveitadas para aumentar o conhecimento e potencializar o aprendizado no contexto rural. Viero e Silveira (2011) afirmam que a internet tornou-se uma necessidade para o rural, da mesma forma que já era para o urbano, visando oferecer informações atualizadas em uma rede interativa.

Nesse sentido, o estudo de campo revelou que entre as possibilidades de uso das TICs pela agricultura familiar está a pesquisa de preços, atividades ou serviços governamentais, comércio eletrônico, além de atuar na mediação entre as famílias, proporciona o aperfeiçoamento educacional, pessoal e produtivo dos membros. As TICs também tornaram-se essenciais para a compreensão das dinâmicas do Desenvolvimento Regional, especialmente no âmbito dos municípios analisados, na medida em se apresentam como dimensões significativas para o desenvolvimento das atividades produtivas e sociais dos estabelecimentos rurais.

\footnotetext{
Considerando a desatenção sobre o espaço rural na área da Comunicação, em especial quando se trata de uma pesquisa sobre a presença e os múltiplos usos de tecnologias de informação e comunicação que adota um entendimento de relações mútuas entre tecnologia, cultura e sociedade, bem como a carência, no âmbito dos estudos sobre desenvolvimento regional, de uma perspectiva desse tipo na análise de referido objeto, ambicionamos ter construído uma tessitura interdisciplinar dessas duas áreas, possibilitando o tratamento de uma realidade conforme indicações anteriores (ESCOSTEGUY; FELIPPI; SIFUENTES, 2020, p. 228).
}

A afirmação de Escosteguy, Felippi e Sifuentes (2020) aponta também para uma vinculação significativa entre desenvolvimento e comunicação. Nesse sentido, percebe-se a importância da análise do desenvolvimento a partir dos diálogos com a comunicação e a relevância de estudos sobre essa temática, em que as TICs se tornam fundamentais para a compreensão do desenvolvimento dos territórios.

Apesar das inúmeras possibilidades oferecidas pelas TICs, os dados apresentados por este estudo de campo revelam limitações do próprio sistema técnico, pois mesmo o produtor fazendo um investimento significativo, o serviço oferecido ao usuário é insatisfatório, o que impossibilita a plena utilização do uso potencial que as TICs oferecem. 
O sinal de telefone é meio fraco, é regular. A internet é móvel, eu até queria instalar a internet, mas aqui não deu aquela via rádio, não chegava à antena que tem pra cá, porque tem o reflorestamento na frente. Aí não tem como instalar (AF 30).

Quando o tempo está pra chuva cai, durante o dia também, fica caindo. A torre é perto, mas o sinal é fraco (AF 7).

Os relatos apresentados neste estudo se assemelham ao estudo de Nagel (2012), que revela que, entre as barreiras e limitações para a adoção das TICs pelos agricultores familiares, a conectividade é a principal barreira, tanto pela disponibilidade escassa, quanto pelos elevados preços e baixa qualidade na maioria dos casos. De igual modo, Viero e Silveira (2011), apontam que a infraestrutura é um dos maiores problemas nas áreas rurais, além da falta de conteúdo específico para essas comunidades.

De acordo com Richardson (1997), o problema de infraestrutura de telecomunicações no meio rural é reconhecido como um dos fatores que têm motivado a migração das pessoas de áreas rurais para as urbanas. O autor relata que agentes de desenvolvimento acreditam que uma condição boa na infraestrutura de telecomunicação rural apodera ser um grande reforço para o desenvolvimento econômico. O relato de Richardson apontava para a necessidade, ainda em 1997, de uma boa infraestrutura como uma maneira de diminuir a migração para áreas urbanas. Passados mais de 20 anos, os mesmos problemas continuam sendo observados no presente objeto de pesquisa. $O$ relato de um produtor entrevistado evidencia a baixa qualidade de conexão, o que dificulta a realização de atividades mais complexas a partir do uso das TICs.

A antena é próxima, mas a internet é fraca, fica caindo com frequência. No celular vai, mas no computador, pra coisas mais pesadas, é difícil (AF 10).

A qualidade está relacionada com a capacidade da conexão oferecida pelo sistema técnico para que os usuários possam explorar o potencial das TICs. Isso requer boa continuidade do sinal e velocidades eficientes para que os conteúdos e operações possam ser acessados e realizados pelos usuários. Nessa perspectiva, a baixa qualidade do sinal dificulta operações mais complexas que requerem uma velocidade maior (NAGEL, 2012).

Os limites relacionados ao acesso impedem o uso e apropriação das múltiplas dimensões de empoderamento da agricultura familiar pelas TICs. Conceição (2016), demonstrou que os agricultores familiares visualizam e utilizam a internet como um fator que contribui para a construção de capacidades econômicas, sociais e cognitivas, de modo a facilitar o desenvolvimento rural como um todo. Nessa perspectiva, evidenciou-se uma constante busca por parte das famílias entrevistadas em acompanhar essa nova dinâmica e inserir-se na sociedade da informação, sendo que os jovens são os principais coadjuvantes nesse processo.

Baseado nos dados deste estudo de campo, observa-se que as TICs são significativas para o desenvolvimento das atividades produtivas e sociais no campo. Apesar das expressivas possibilidades, o uso das TICs pela agricultura familiar 
apresenta limitações, relacionadas principalmente ao sistema técnico estabelecido. O problema de infraestrutura de telecomunicações no meio rural muitas vezes impede o uso efetivo do potencial que as TICs oferecem, e, por conseguinte, o desenvolvimento dos territórios.

\section{Considerações finais}

O objetivo desta pesquisa foi analisar o uso das TICs por famílias agricultoras da região Sul do Brasil, apontando as possibilidades e limites no contexto da agricultura familiar. A partir do estudo de campo, percebeu-se que as TICs se tornaram tecnologias habituais e se configuram como parte do cotidiano das famílias agricultoras, em maior ou menor grau.

A configuração do espaço rural estudado é bastante heterogênea, diversificada e dinâmica. Constatou-se que, das 30 unidades familiares entrevistadas, 19 possuem até um módulo fiscal, o que fica evidente que as explorações está em função do tamanho da propriedade, sendo as menores propriedades as mais diversificadas.

$\mathrm{O}$ acesso às TICs significa a possibilidade de outros acessos relacionados à comunicação, intercâmbio de informações, acesso a serviços bancários, educação à distância, assistência técnica, acesso a novos mercados, entre outros serviços. A possibilidade de acessar e usar as TICs representa aos agricultores familiares e aos atores envolvidos nas dinâmicas do rural um empoderamento e uma necessidade frente à competitividade do mercado atual.

Apesar da importância e significado que as TICs representam ao meio rural, o estudo de campo revela que as condições desse acesso apresentam limitaçõos. $O$ sistema técnico é deficitário, em virtude das condições de infraestrutura de telecomunicações no meio rural, que na maioria das vezes, impede o efetivo acesso a todo o potencial que detém essas tecnologias. Em alguns casos, mesmo com um investimento elevado o agricultor não consegue acessar um serviço melhor ou mesmo, usar adequadamente.

Os achados de pesquisa sobre a temática permitem considerar a importância de políticas públicas que considerem a inclusão do campo também no contexto tecnológico; a evidenciação de que tal temática está inserida numa arena de disputas no qual o sistema sociotécnico hegemônico reforça o campo como espaço periférico. Ao mesmo tempo, o estudo demonstra as mudanças no contexto do compartilhamento de saberes, implicações na extensão rural e no contexto da convivialidade e permanência da juventude no campo, e especialmente das perspectivas históricas de resistências no contexto da agricultura familiar.

\section{REFERÊNCIAS}

ABRAMOVAY, R. O capital social dos territórios: repensando o desenvolvimento rural. Economia Aplicada, v. 4, n. 2, p. 379-397, 2000.

BLANCO, A.; CÀNOVES, G. Las tecnologías de la información y la comunicación en el desarrollo del turismo rural. Documents d'Anàlisi Geogràfica, n. 46, p.105-117, 2005. 
BRANDEMBURG, A. Do Rural Tradicional ao Rural Socioambiental. Ambiente \& Sociedade, v. 13, n. 2, p. 417-428, 2010.

BRASIL. Lei $\mathbf{n}^{\circ}$ 11.326, de 24 de julho de 2006. Estabelece as diretrizes para a formulação da Política Nacional da Agricultura Familiar e Empreendimentos Familiares Rurais. Disponível em: <http://www.planalto.gov.br/ccivil_03/_ato20042006/2006/lei/l11326.htm>. Acesso em: 23 jul. 2018.

CASTELLS, M. A sociedade em rede. A era da informação: economia, sociedade e cultura. Volume 1. São Paulo: Paz e Terra, 2010.

CENTENO, M. Jóvenes, comunicación y tecnologías: estrategias para afrontar la incertidumbre. In: VIZER, E. A.; BARICHELLO, E.; SILVEIRA, A. C. M. da. (Org.). Rural Conectado. Mídia e processos sociotécnicos no Brasil e Argentina. Santa Maria: FACOS, 2016, p. 133-167.

CONCEIÇÃO, A. F. da. "Quem está online?" - um estudo de caso sobre o uso e apropriação da internet por agricultores familiares de Estrela/RS. Dissertação (Mestrado em Extensão Rural), Universidade Federal de Santa Maria, Santa Maria, 2012.

CONCEIÇÃO, A. F. da. Internet pra quê? - A Construção de Capacidades e as TICs no processo de Desenvolvimento Rural. Tese (Doutorado em Desenvolvimento Rural), Universidade Federal do Rio Grande do Sul, Porto Alegre, 2016.

CONCEIÇÃO, A. F. da; FREITAS, A. F. de. Cadeias Curtas e Internet: utilização de estratégias de comunicação na conexão entre consumidores e produtores. In: SIMPÓSIO SOBRE REFORMA AGRÁRIA E QUESTÕES RURAIS, VIII, 2018. Anais... Uniara, 2018, p. 1-15.

CROVI, D. Dimensión social del acceso, uso y apropiación de las TIC. Contratexto, $\mathrm{n}$. 16, p. 65-79, 2008.

DUARTE, J.; CASTRO, A. M. G. de. Comunicação e tecnologia na cadeia produtiva da soja em Mato Grosso. Brasília: Embrapa Informação Tecnológica, 2004.

ESCOSTEGUY, A. C. D.; FELIPPI, A. C. T.; SIFUENTES, L. Reconfigurações do espaço rural e do cotidiano familiar: os sujeitos e suas práticas com as tecnologias de comunicação. Revista Redes, v.25, n.1, p. 211-231, 2020.

ESCOSTEGUY, A. C. D.; SIFUENTES, L.; BIANCHINI, A. F. Mulheres trabalhadoras rurais do Vale do Sol e suas práticas com as TICs. In: ESCOSTEGUY, A. C. D.; FELIPPI, A. C. T.; SIFUENTES, L. (et al.). As tecnologias de comunicação no cotidiano de famílias rurais: (re) configurações de uma ruralidade. Santa Cruz do Sul: EDUNISC, 2019, p. 168-181. 
FELIPPI, A. C. T.; GUERIN, Y. S.; OLIVEIRA, V. G. Jovens rurais de Vale do Sol e suas práticas com as TICs. In: ESCOSTEGUY, A. C. D.; FELIPPI, A. C. T.; SIFUENTES, L. (et al.). As tecnologias de comunicação no cotidiano de famílias rurais: (re) configurações de uma ruralidade. Santa Cruz do Sul: EDUNISC, 2019, p. 168-181.

FELIPPI, A. C. T.; ESCOSTEGUY, A. C. D. Juventude rural e novas formas de sociabiliade: um estudo do uso do celular no Sul do Brasil. Revista Latino-americana de Ciências da Comunicação, v. 14, n. 26, p. 140-150,2017.

GIL, A. C.Métodos e técnicas de pesquisa social. $6^{\mathrm{a}}$ ed. $3^{\mathrm{a}}$ reimpr., São Paulo: Atlas, 2010.

INSTITUTO BRASILEIRO DE GEOGRAFIA E ESTATÍSTICA (IBGE). Agência IBGE notícias. Censo Agro 2017: resultados preliminares mostram queda de $2,0 \%$ no número de estabelecimentos e alta de $5 \%$ na área total. Disponível em: <https://agenciadenoticias.ibge.gov.br/agencia-sala-de-imprensa/2013-agencia-denoticias/releases/21905-censo-agro-2017-resultados-preliminares-mostram-queda-de2-0-no-numero-de-estabelecimentos-e-alta-de-5-na-area-total.html>. Acesso em: 29 jul. 2018.

INSTITUTO BRASILEIRO DE GEOGRAFIA E ESTATÍSTICA (IBGE). Censo Agropecuário 2006. Número dos estabelecimentos agropecuários com agricultura familiar e não familiar. Disponível em: <https://sidra.ibge.gov.br/Tabela/1966\#resultado>. Acesso em: 31 out. 2018.

INSTITUTO BRASILEIRO DE GEOGRAFIA E ESTATÍSTICA (IBGE). Pesquisa Nacional por Amostra de Domicílios Contínua - PNAD. Acesso à Internet e à televisão e posse de telefone móvel celular para uso pessoal 2017.Disponível em: < https://biblioteca.ibge.gov.br/index.php/bibliotecacatalogo?view=detalhes\&id=2101631>. Acesso em: $10 \mathrm{fev.} 2019$.

LARDONE, L. Digitalización de la vida social rural. ¿Época de cambios o cambio de época? In: CENTENO, Matias (Org.). Vida digital: nuevos medios, sociedad y transformaciones. San Luis: Ediciones INTA, 2013.

MINAYO, M. C. de S. (Org.). Pesquisa Social. Teoria, método e criatividade. Petrópolis: Editora Vozes, 2009.

NAGEL, J.Principales barreras para la adopción de las TIC en la agricultura y en las áreas rurales. Comisión Económica para América Latina y el Caribe (2012). Disponível em:

<https://repositorio.cepal.org/bitstream/handle/11362/4011/S2012079_es.pdf?sequen ce=1\&isAllowed=y> Acesso em: 23 set. 2019 .

PROULX, S. Paradigmas para pensar os usos dos objetos comunicacionais. In: PROULX, S.; FERREIRA, J.; ROSA, A. P. da (Orgs.). Midiatização e redes digitais: os 
usos e as apropriações entre a dádiva e os mercados. Santa Maria: Facos-UFSM, 2016, p. 41-58.

RICHARDSON, D. The Internet and Rural \& Agricultural Development: Integrated Approach. FAO. Rome, 1997.

SCHWARTZ, C. Relações de gênero e apropriação de tecnologias de informação e comunicação na agricultura familiar de Santa Maria - RS. Tese (Doutorado em Extensão Rural), Universidade Federal de Santa Maria, Santa Maria, 2012.

SILVA, M. G. A apropriação de TICs por extensionistas e agricultores familiares: uma leitura a partir da teoria da comunicação linear e em rede. In: VIZER, E. A.; BARICHELLO, E.; SILVEIRA, A. C. M. da. (Org.). Rural Conectado. Mídia e processos sociotécnicos no Brasil e Argentina. Santa Maria: FACOS, 2016, p. 52-75.

THOMPSON, J. B. A mídia e a modernidade: uma teoria social da mídia. Petrópolis: Editora Vozes, 2008.

THORNTON, R. El agricultor, Internet y las barreras a su adopción. In: THORNTON, R.; CIMADEVILLA, G. La extensión rural en debate. Buenos Aires: INTA, 2003.

TORRES, T. Z. et al. As tecnologias digitais no fluxo informacional do espaço rural brasileiro. In: CONGRESO INTERNACIONAL DE CIDADES CRIATIVAS, III, 2013. Anais... Madrid, 2013, p. 1219- 1236.

VIERO, V. C.; SILVEIRA, A.C. M. Apropriação de tecnologias de informação e comunicação no meio rural brasileiro. Cadernos de Ciência \& Tecnologia, v. 28, n. 1, p. 257-277, 2011.

VIERO, V; SOUZA, R. Comunicação rural on line: promessa de um mundo sem fronteiras - estudo de caso do modelo de monitoramento agrícola do Sistema Irriga da Universidade Federal de Santa Maria. In: CONGRESSO BRASILEIRO DE ECONOMIA, ADMINISTRAÇÃO E SOCIOLOGIA RURAL, XLVI, 2008. Anais... Rio Branco, 2008, p. 1-14.

Wilson Itamar Godoy. Universidade Tecnológica Federal do Paraná. E-mail: godoyutfpr@gmail.com

Andressa Sanssanoviez. Universidade Tecnológica Federal do Paraná. E-mail: andressajornalista27@gmail.com

Giovanna Pezarico. Universidade Tecnológica Federal do Paraná. E-mail: gpezarico@gmail.com 


\section{Submetido em: 13/02/2020}

Aprovado em: 30/05/2020

Como citar: GODOY, Wilson Itamar; SANSSANOVIEZ, Andressa; PEZARICO, Giovanna. Limites e possibilidades do uso das TICs pela agricultura familiar na região Sul do Brasil. Redes (St. Cruz Sul, Online), Santa Cruz do Sul, v. 25, p. 2086-2104, 2020. ISSN 19826745. doi:https://doi.org/10.17058/redes.v25i0.14768.

\section{CONTRIBUIÇÃO DE CADA AUTOR}

a. Fundamentação teórico-conceitual e problematização: Wilson Itamar Godoy, Andressa Sanssanoviez, Giovanna Pezarico

b. Pesquisa de dados e análise estatística: Andressa Sanssanoviez

c. Elaboração de figuras e tabelas: Andressa Sanssanoviez

d. Fotos: Não possui

e. Elaboração e redação do texto: Wilson Itamar Godoy, Andressa Sanssanoviez, Giovanna Pezarico

f. Seleção das referências bibliográficas: Wilson Itamar Godoy, Andressa Sanssanoviez, Giovanna Pezarico

Fontes de financiamento: Coordenação de Aperfeiçoamento Pessoal de Nível Superior (CAPES). 